\title{
Hydrodynamics of long-duration urban floods: experiments and numerical modelling
}

\author{
Anaïs Arrault ${ }^{1,3}$, Pascal Finaud-Guyot ${ }^{2}$, Pierre Archambeau ${ }^{1}$, Martin Bruwier ${ }^{1}$, Sébastien Erpicum ${ }^{1}$, \\ Michel Pirotton ${ }^{1}$, and Benjamin Dewals ${ }^{1}$ \\ ${ }^{1}$ Research group HECE, Department ArGEnCo, University of Liege, Liege, Belgium \\ ${ }^{2}$ ICube, Université de Strasbourg, CNRS - UMR7357, ENGEES, 2 rue Boussingault, Strasbourg, France \\ ${ }^{3}$ Ecole Nationale Supérieure des Mines d'Ales, 6 Avenue de Clavières 30319 Ales CEDEX, France \\ Correspondence to: Benjamin Dewals (b.dewals@ulg.ac.be)
}

Received: 11 January 2016 - Published in Nat. Hazards Earth Syst. Sci. Discuss.: 11 February 2016

Revised: 12 May 2016 - Accepted: 26 May 2016 - Published: 16 June 2016

\begin{abstract}
Flood risk in urbanized areas raises increasing concerns as a result of demographic and climate changes. Hydraulic modelling is a key component of urban flood risk analysis; yet, detailed validation data are still lacking for comprehensively validating hydraulic modelling of inundation flow in urbanized floodplains. In this study, we present an experimental model of inundation flow in a typical European urban district and we compare the experimental observations with predictions by a 2-D shallow-water numerical model. The experimental set-up is $5 \mathrm{~m} \times 5 \mathrm{~m}$ and involves seven streets in each direction, leading to 49 intersections. For a wide range of inflow discharges, the partition of the measured outflow discharges at the different street outlets was found to remain virtually constant. The observations also suggest that the street widths have a significant influence on the discharge partition between the different streets' outlets. The profiles of water depths along the streets are mainly influenced by the complex flow processes at the intersections, while bottom roughness plays a small part. The numerical model reproduces most of the observed flow features satisfactorily. Using a turbulence model was shown to modify the length of the recirculations in the streets, but not to alter significantly the discharge partition. The main limitation of the numerical model results from the Cartesian grid used, which can be overcome by using a porosity-based formulation of the shallow-water equations. The upscaling of the experimental observations to the field is also discussed.
\end{abstract}

\section{Introduction}

Floods are the most common natural hazard. In Europe, they caused around EUR 100 billion of damage between 1986 and 2006 (de Moel et al., 2009). Many cities were built along rivers, deltas or in coastal areas and are therefore partly located in the floodplains. Urban flood risk management is of particularly high relevance as urbanization is growing at an unprecedented pace and hydrological extremes tend to increase in magnitude and frequency (Domeneghetti et al., 2015; Merz et al., 2012; Vorogushyn and Merz, 2013). Reliable predictions of flood hazard are a prerequisite to support contemporary flood risk management policies. This includes the accurate estimation of inundation extents, water depths, discharge partition and flow velocity in urbanized floodplains, since these parameters are critical inputs for flood impact modelling (Brazdova and Riha, 2014; Kellermann et al., 2015; Kreibich et al., 2014).

Models based on the shallow-water equations are the most common approach for detailed inundation modelling (Costabile and Macchione, 2015). They are considered as state-ofthe-art for large-scale real-world applications and have been the focus of much research over the last 2 decades. They also benefit from widely available detailed datasets obtained from remote sensing techniques, such as laser altimetry (Dottori et al., 2013). Difficulties remain nonetheless for estimating the roughness parameters which may vary significantly in space, particularly in floodplains. 
Different state-of-the-art hydraulic models exist to compute the inundation characteristics. However, their validation for urban flood configurations remains incomplete as reference data from the field are relatively scarce and difficult to obtain (Dottori et al., 2013; El Kadi Abderrezzak et al., 2009; Neal et al., 2009). Water marks and aerial imagery provide some relevant information but they remain affected by high uncertainties. They are also far from sufficient to reflect the whole complexity of inundation flows in densely urbanized floodplains, the proper description of which requires information on the velocity fields and discharge partitions.

To address this lack of validation data, scale model studies are particularly valuable, since they deliver accurate measurements of flow characteristics under controlled hydraulic conditions (e.g. known distribution of inflow discharge and downstream boundary conditions). Several experimental studies of relevance have been conducted, mainly during the last decade. They have involved different degrees of complexity and realism in the considered flow configurations, ranging from isolated street intersections up to complete urban districts with surface and underground flow.

The flow behaviour in intersections is an essential component of urban flooding since an urban district may be seen as a network of streets and intersections. A limited number of experimental studies investigated specifically the flows at street intersections.

Weber et al. (2001) presented detailed 3-D flow and turbulence measurements at a $90^{\circ}$ open-channel junction.

Mignot et al. (2008) studied a junction of four branches, with supercritical inflow from two branches. They identified three different flow regimes, depending on the location of hydraulic jumps (either in the upstream channels or within the junction).

Based on 220 experiments, Rivière et al. (2011) studied subcritical flow in a four-branch open-channel intersection. They derived an empirical correlation for the flow partition as a function of the inflow discharges and the height of downstream weirs.

El Kadi Abderrezzak et al. (2011) and Rivière et al. (2014) studied transcritical flow at three- and four-branch intersections. Unlike previously assumed, the existence of a critical section in the lateral channel was shown not to ascertain that flow in the intersection is decoupled from downstream flow conditions. They correlated the partition of outflow discharge with the Froude number and the upstream critical depth. All these studies were conducted for a single intersection only and considering right angles as well as channels of equal width.

Mignot et al. (2013) studied the flow in a three-branch bifurcation with one or several obstacles representing, for instance, pieces of urban furniture. Nine obstacle configurations were considered, which lead to very different influences on the flow. Bazin (2013) confirmed the importance of including such small-scale obstacles within urban flood models explicitly.
Using the same experimental facility as Mignot et al. (2013), Bazin (2013) also considered the influence of sidewalks in a three-branch bifurcation with subcritical flow. Comparing the experimental observations with results of 2D modelling, he points out that, on the scale of a single crossroad with subcritical flow, a bias in the average ground elevation leads to errors in the estimation of discharge partition in the streets. Based on a physical model of an urban drainage system, Bazin (2013) and Bazin et al. (2014) also validated an analytical model predicting the discharge exchange between surface flow and underground pipe flow.

Instead of focusing on a single street intersection, other experimental studies analysed the flow field in a whole urban district. They are, however, very rare and we could only identify five significant contributions.

Zech and Soares-Frazão (2007) investigated transient flow in an idealized urban district located on a scale model of Toce Valley in Italy. Two different layouts of 20 building blocks were considered (aligned vs. staggered). Water depths were measured by electrical conductivity gauges at some locations around and within the urban district. However, they do not provide a truly distributed view of the flow pattern over the whole urban district. Considering a simplified geometric setting with a flat topography, similar tests were conducted by Soares-Frazão and Zech (2008) under transient flow conditions in an experimental flume. The idealized urban district was made of $5 \times 5$ building blocks, either aligned or inclined with respect to the main flow direction. Water levels were measured at approximately 100 points. Large-scale particle image velocimetry (LS-PIV) was used to estimate the surface velocity field. For these two models with transient flow, boundary conditions were difficult to manage and the discharge partition between the different streets was not investigated at all.

Ishigaki et al. (2003) used a scale model of a $1 \mathrm{~km} \times 2 \mathrm{~km}$ district of Kyoto to highlight the importance of underground space (parking lots, subway platforms ...) during moderate floods of limited duration. Water depths were measured in eight locations using ultrasonic sensors, while the surface velocity field was measured by LS-PIV. About $50 \%$ of the inflow volume was found to reach the underground space.

A scale model of 17 th Street of New Orleans was used by Sattar et al. (2008) to study the urban flooding induced by a dike breach during hurricane Katrina in 2005. The model was designed to evaluate the viability of using sandbags in a multibarrier configuration to effectively close the breach. The flow in the urbanized floodplain was represented to properly reflect its influence on the tailwater at the breach location. Water depths were measured at about 800 points using mechanical gauges, and flow velocity was measured by a micro acoustic Doppler velocimeter, at a limited number of grid points, mainly outside the urbanized area. The outflow discharge was measured in each street.

Paquier et al. (2009) set up two laboratory models (scales $1: 100$ and $1: 24$ ) to investigate the effects of non-structural 
measures such as urban development enabling temporary flood storage or car park regulations, which contribute to the preservation of the optimal flow conveyance in the streets during flood events.

Lipeme Kouyi et al. (2010) describe experiments in an idealized urban district. The district consists of seven streets aligned from north to south, crossing seven other streets aligned from west to east. Most streets are not straight; therefore complex geometric configurations arise at the intersections. The scale factor is 100 horizontally and 25 vertically. Only steady flows were considered and the set-up did not enable direct control of the partition of the inflow discharge between the different streets. Walls were positioned west and east of the district, so that only a single main flow direction could be analysed.

In the present study, we consider the Icube Laboratory model of a typical European district, similar to the configuration considered by Lipeme Kouyi et al. (2010). However, here, the boundary conditions allow for the flow distribution to be varied continuously between west-east and north-south directions. The present set-up enables the inflow discharge to be controlled independently in each street. We focus on steady flow conditions, which constitute a realistic approximation for long-duration floods.

The study provides new insights into the distribution of water depths and the discharge partition in a more general urban setting than considered in previous research. The experimental dataset is available for testing numerical models and we provide here a comparison with the results of one specific model, namely WOLF 2-D, which has been widely used for inundation mapping (Erpicum et al., 2010a) and in flood risk analysis research (Beckers et al., 2013; Bruwier et al., 2015; Detrembleur et al., 2015; Ernst et al., 2010).

The experimental and numerical models are presented in Sect. 2. The influence of varying the total inflow discharge is analysed in Sect. 3, together with a sensitivity analysis of the computed results considering different roughness parameters, grid spacing and turbulence models. Section 4 details how the partition of the inflow discharge influences the results. In Sect. 5, the upscaling of the experimental findings to real-world applications is discussed, as well as the enhancements brought by an improved modelling of the streets' geometry and the possible extension of the results to unsteady flow conditions. Conclusions and perspectives are given in Sect. 6.

\section{Methods}

\subsection{Experiments}

The experiments considered here were conducted by Araud (2012) at the laboratory ICube in Strasbourg (France). Compared to previous studies, the experimental set-up achieves a relatively high degree of realism by involving

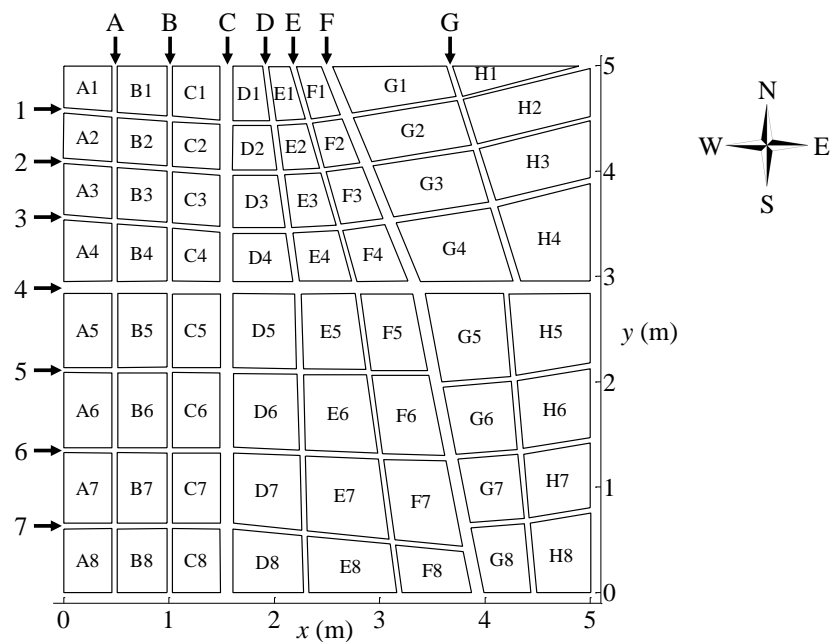

Figure 1. Plane view of the idealized urban district considered in the experiments. Adapted from Araud (2012).

streets of various widths and intersections of different types (both normal branches and branches of different inclinations). The study focused on long-duration and extreme events; i.e. a steady state was considered and the flow through the underground networks was assumed negligible and was not reproduced in the model. Only an overview of the experimental set-up and procedure is given here, while all details were described by Araud (2012).

\subsubsection{Laboratory set-up}

The experimental set-up represents an idealized urban district. It extends over $5 \mathrm{~m} \times 5 \mathrm{~m}$, has a horizontal bottom and contains 64 impervious blocks in Plexiglass (Fig. 1). These blocks define a total of 14 streets. Seven of them (denoted 1 to 7) are aligned in the east-west direction, while seven other streets (noted A to G) follow the north-south direction. All streets have a width of $5 \mathrm{~cm}$, except streets $4, \mathrm{C}$ and $\mathrm{F}$ which are $12.5 \mathrm{~cm}$ wide. The coordinates of the geometry of the model are provided in Araud (2012). They correspond to the "as-built" coordinates of the obstacles.

The street inlets are located along the north and west faces of the model, while the outlets are on the south and east faces. Fourteen pumps were used to control the inflow discharge into each street individually. The discharge was distributed between the streets of each face proportionally to their widths. The model was fed with water, assuming no sediment transport and no debris in the flow. The outlets enable free-flow conditions thanks to chutes.

\subsubsection{Instrumentation}

The outflow discharge in each street was determined from the rating curve of calibrated weirs located downstream of the street outlets. An ultrasound sensor was used for mea- 
suring the water level upstream of each weir. With a measurement window of minimum $40 \mathrm{~s}$, the uncertainty of the outflow discharge was shown to remain below $3.5 \%$ (Araud, 2012). Given the calibration procedure of the regulation system of the pumps, the uncertainty of the inflow discharge is the same as for the outflow discharge $(3.5 \%)$.

The water depths along the centreline of the streets were measured by an optical gauge fixed on an automatic traverse system. The gauge detects the phase (air vs. water) in which it is located. Due to the relatively slow operation of this system, water depths could only be measured along the centreline of the streets, at about 600 different locations in total. The measurement uncertainty results mainly from the accuracy of the motor, which was estimated at $\pm 1 \mathrm{~mm}$. The overall uncertainty depends also on the fluctuations of the free surface. Throughout most of the experimental model, these fluctuations did not exceed $1 \mathrm{~mm}(2 \mathrm{~mm}$ for the considered highest discharge). The fluctuations locally reached 4 to $10 \mathrm{~mm}$ downstream of the intersections between the main streets $(4$, $\mathrm{C}$ and $\mathrm{F}$ ) and downstream of the intersections located close to the south-east corner of the model (Araud, 2012).

\subsubsection{Test program}

Two main series of experiments were considered here. In the first series, the total inflow discharge was varied from 10 up to $100 \mathrm{~m}^{3} \mathrm{~h}^{-1}$, with three intermediate values of discharge $\left(20,60\right.$ and $\left.80 \mathrm{~m}^{3} \mathrm{~h}^{-1}\right)$ as detailed in Table 1 . In all the tests of this first series, the partition of inflow discharge was kept equal between the west and the north faces. These discharges are consistent with those observed in previous flood events in dense urban floodplains (Mignot et al., 2006), scaled according to the Froude similarity as detailed in Supplement 1. In the second series of tests, the total inflow was kept at a constant value $\left(60 \mathrm{~m}^{3} \mathrm{~h}^{-1}\right)$ and the inflow partition between the west and north faces was varied systematically from 0 up to $100 \%$ by steps of $10 \%$ (Table 1 ).

The outflow discharge was measured downstream of each street for all the tests. In addition, for the tests of the first series of experiments (except for $10 \mathrm{~m}^{3} \mathrm{~h}^{-1}$ ), the water levels were measured along all the streets.

The reproducibility of the experiments was tested by comparing water depth and discharge measurements on experiments repeated at several day intervals. The upstream and downstream boundary conditions were identical for all the repetitions. For instance, for test Q020-050, a difference of less than $1 \mathrm{~mm}$ was found on $90 \%$ of replicate measurements of water depth. This difference corresponds to the resolution of the measuring device. $96 \%$ of the differences were lower than $2 \mathrm{~mm}$, which corresponds roughly to the fluctuations of the free surface for this test. The outflow discharges in all the streets were measured 13 times. The observed differences were also of the order of the measurement uncertainties (Araud, 2012).
Table 1. Test series dedicated to testing the influence of the total inflow of the inflow partition between the west and north faces.

\begin{tabular}{|c|c|c|c|}
\hline & Test ID & $\begin{array}{r}\text { Total } \\
\text { inflow } \\
\text { discharge } \\
\left(\mathrm{m}^{3} \mathrm{~h}^{-1}\right)\end{array}$ & $\begin{array}{r}\text { Portion of } \\
\text { inflow } \\
\text { through } \\
\text { the north } \\
\text { face }(\%)\end{array}$ \\
\hline \multirow{5}{*}{ 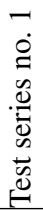 } & Q010-W050 & 010 & 50 \\
\hline & Q020-W050 & 020 & 50 \\
\hline & Q060-W050 & 060 & 50 \\
\hline & Q080-W050 & 080 & 50 \\
\hline & Q100-W050 & 100 & 50 \\
\hline \multirow{11}{*}{ 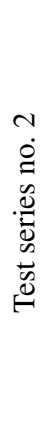 } & Q060-W000 & 60 & 0 \\
\hline & Q060-W010 & 60 & 10 \\
\hline & Q060-W020 & 60 & 20 \\
\hline & Q060-W030 & 60 & 30 \\
\hline & Q060-W040 & 60 & 40 \\
\hline & Q060-W050 & 60 & 50 \\
\hline & Q060-W060 & 60 & 60 \\
\hline & Q060-W070 & 60 & 70 \\
\hline & Q060-W080 & 60 & 80 \\
\hline & Q060-W090 & 60 & 90 \\
\hline & Q060-W100 & 60 & 100 \\
\hline
\end{tabular}

In the laboratory experiments, the Reynolds numbers $R=4 h u / v$ takes values of the order of $10^{4}-10^{5}$ ( $h$ is the water depth, $u$ the depth-averaged velocity and $v$ the kinematic viscosity of water). At the prototype scale, $R$ is expected to reach $10^{6}-10^{7}$, as discussed in Sect. 5.2. The Froude number $F=u /(g h)^{0.5}$ is in the range $0.15-0.4$ at the inlet of the streets ( $g$ is the gravity acceleration).

\subsection{Numerical model}

The ability of a standard shallow-water model to predict the observed discharge partitions and water depths was tested using the numerical model WOLF 2-D. This model has been developed by the research group HECE of the University of Liege (Belgium). It solves the fully dynamic shallowwater equations on multiblock Cartesian grids and a twolength scale $k-\varepsilon$ turbulence model is used to account for the anisotropic turbulent mixing induced by the lateral shear and by the bottom-generated turbulence (Camnasio et al., 2014; Erpicum et al., 2009). The numerical discretization is based on a conservative finite volume scheme and a self-developed flux vector splitting (Dewals et al., 2008; Erpicum et al., 2010b).

In 2003, the model WOLF 2D was selected by the regional authorities in Belgium to perform all detailed 2-D flow simulations to support official inundation mapping, including in the framework of the European Floods Directive. Since then, it has been routinely applied for inundation modelling. 
In the applications considered here, the bottom shear stress was estimated using the Darcy-Weisbach formulation and the friction coefficient was evaluated by the Colebrook formula as a function of a roughness height $k$ defined by the modeller. This formulation was preferred here to the Manning formula because it is more process-oriented and enables therefore a more objective estimation of the corresponding roughness parameter (roughness height vs. Manning coefficient). In addition, the experimental conditions do not guarantee a hydraulic rough flow regime, which is necessary for applying the Manning formula. Unless otherwise stated, all simulations were performed with a roughness height of zero, consistently with the smooth walls and bottom of the experimental model.

The geometry of the scale model was implemented in the numerical model by using the building hole method (Schubert and Sanders, 2012). The cell size is uniform and was taken equal to $1 \times 1 \mathrm{~cm}^{2}$. This choice was made to obtain a realistic number of cells over the width of each streets (about 7 to 12) compared to the relative grid resolution used in practice for inundation modelling. Results obtained with a cell size of $5 \times 5 \mathrm{~mm}^{2}$ are also discussed (Sect. 3.2).

The inflow discharge was prescribed as a boundary condition upstream of each street, while a free flow was considered at the downstream boundaries. The boundary conditions for the turbulence model were set according to Camnasio et al. (2014) and Choi and Garcia (2002).

The time step used in the computations is optimized based on the Courant-Friedrichs-Lewy (CFL) stability condition (e.g. Bates et al., 2010). It takes values of the order of $10^{-3} \mathrm{~s}$ for simulations of the laboratory model and $5 \times 10^{-2} \mathrm{~s}$ for the prototype scale.

\section{Influence of inflow discharge}

In a first series of tests, the total inflow discharge was varied from 10 to $100 \mathrm{~m}^{3} \mathrm{~h}^{-1}$, while preserving an equal distribution of inflow discharge between the west and north faces. In Sect. 3.1, we describe the experimental observations and the computational results based on the numerical model introduced in Sect. 2.2. Next, we show the influence of modelling choices such as the grid refinement, the turbulence model and the roughness parameter (Sect. 3.2).

\subsection{Experimental observations and numerical results}

We present hereafter the experimental and numerical results in terms of discharge partition between the south and east faces, as well as at the street level. We also describe the observed and computed water depths, both at the district and at the street levels. In terms of numerical results, this section only discusses the results obtained by using a cell size of $1 \mathrm{~cm}$, the $k-\varepsilon$ turbulence model and the Colebrook fric-

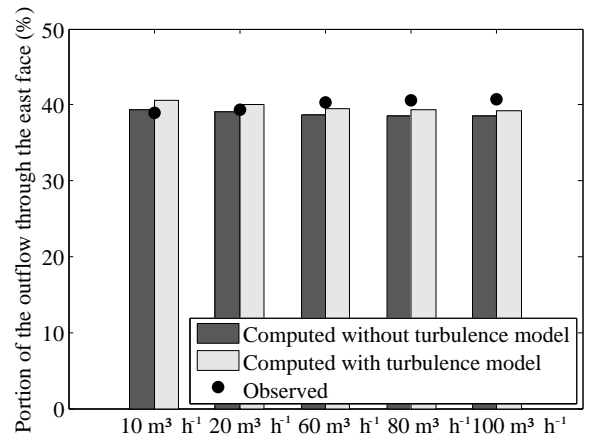

Figure 2. Distribution of outflows between the downstream faces in the observations and for different model characteristics.

tion formula, with a roughness height equal to zero (i.e. von Kármán formula). Variants of this are detailed in Sect. 3.2.

\subsubsection{Discharge partition between the south and east faces}

The circular markers in Fig. 2 represent the observed partition of the outflow discharge between the east and south faces of the urban district for five different total inflow discharges. Overall, about $60 \%$ of the outflow discharge crosses the south face and $40 \%$ the east face. This first distinctive result of the experiments is partly explained by the total flow width available in the north-south direction compared to the west-east direction. Indeed, only one "wide" street (street 4) is aligned in the west-east direction, whereas two of them (streets $\mathrm{C}$ and F) convey the flow in the north-south direction. As a result, the total flow width in the west-east direction is $42.5 \mathrm{~cm}$, which is lower than the total flow width in the north-south direction $(50 \mathrm{~cm})$. Consequently, the available flow width along the east face is $46 \%$ of the total outflow width, whereas it is $54 \%$ for the south face. This difference goes in the same direction as the difference in outflows (40\% vs. $60 \%$ ).

Besides, the observed outflow partition between the south and east faces (60\% vs. $40 \%$ ) remains virtually independent of the total inflow discharge. Indeed, for a total inflow discharge varying by 1 order of magnitude, from 10 up to $100 \mathrm{~m}^{3} \mathrm{~h}^{-1}$, the portion of outflow through the east face varies only from 38.6 to $40.6 \%$. The physical reason for this is explored in Sect. 5.1.

The shallow-water model succeeds in predicting the overall discharge partition between the south and east faces (Fig. 2). The difference between the observed and computed values remains in the range $0.02-2.16 \%$. So, the numerical model also reproduces the quasi-independence of the outflow discharge partition with respect to the total inflow. 


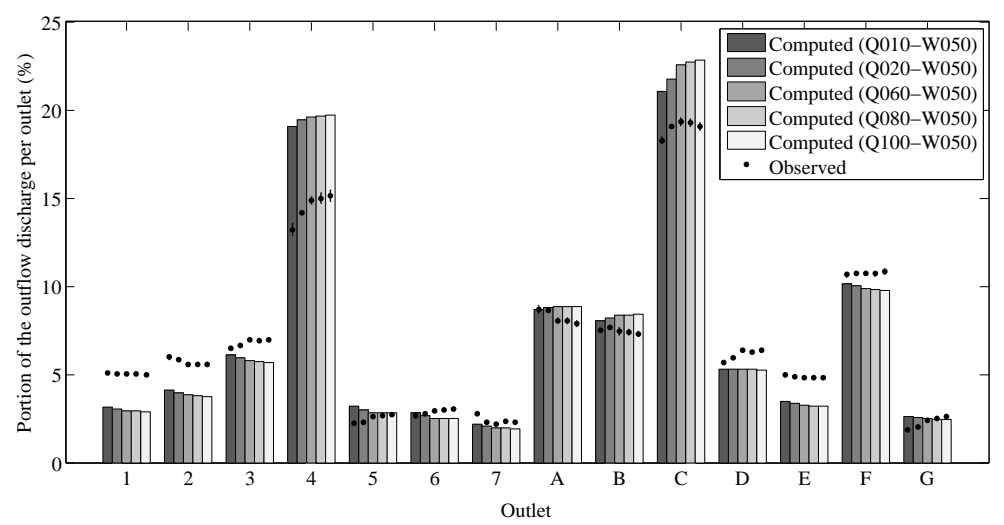

Figure 3. Observed and computed contributions of each street to the total outflow discharge for five different inflow discharges.

\subsubsection{Discharge partition at the street level}

Figure 3 details the partition, street by street, of the outflow discharge for five different inflow discharges. The highest outflow discharges correspond to the widest streets, particularly those which are straight and start more upstream in the model i.e. closer to the north-west corner (streets $\mathrm{C}$ and 4 ).

At the outlet of street $\mathrm{C}$, which is 2.5 times wider than streets $\mathrm{A}$ and $\mathrm{B}$, the observed outflow discharge is about 2.3 to 2.5 times higher than the corresponding discharges in streets A and B. This leads to similar unit discharges in the different streets and may results from the similar configurations of streets A, B and C in terms of shape (all three are straight) and encountered types of intersections. In contrast, street 4 collects between 2 and 3 times more discharge than streets 1,2 and 3, while the ratio of the street widths is also 2.5. These larger deviations may result from the different configurations of streets 1,2 and 3 compared to street 4, since the latter is straight while the former are curved, leading to different types of intersections.

Another example of influence of the shape of the streets and intersections may be noticed by comparing streets 1 and A. Their inflow discharges are the same; but street A has an observed outflow discharge between 60 and $70 \%$ higher than the observed outflow in street 1 . The number of intersections is the same for both streets. However, street A has mostly right-angle intersections, while all intersections in street 1 have different angles, which seems to promote more flow to be diverted towards the lateral streets. The difference in the outflow discharges results most likely from this difference in the shapes of the streets. Similarly, street F, which is as wide as street $\mathrm{C}$, discharges at the outflow only about 55$58 \%$ of the discharge from street $\mathrm{C}$, as street $\mathrm{F}$ is curved and located further from the "upstream" corner (north-west).

Similarly as for the discharge partition between the faces, the observed portion of outflow discharge in each street remains essentially independent of the total inflow (Fig. 3). For a total inflow varying by 1 order of magnitude (from 10 to $100 \mathrm{~m}^{3} \mathrm{~h}^{-1}$ ), the scaled sensitivity of the outflow discharges in the different streets is on average $4 \%$ and it does not exceed $12 \%$, except in street $\mathrm{G}$ where it reaches $19 \%$.

In the computed results, the outflows from the streets with the highest discharges ( 4 and C) are overestimated by 10 $30 \%$ compared to the experimental results. The opposite is observed for some of the streets with the lowest discharges (1-3, D-F), while the outflows from streets 5-7 and $G$ are fairly well represented by the numerical model. The outflow discharges from the streets with intermediate discharges (A, $\mathrm{B}$ and $\mathrm{F}$ ) are also generally well predicted by the model.

As the obtained discrepancies are maximum in curved streets (1,2 and 3), it is likely that they partly result from the Cartesian grid used, which relies on a "staircase" approximation of the obstacles not aligned with the grid. A Cartesian grid remains, however, of high relevance in practice (Kim et al., 2014), as it makes it generally straightforward to handle contemporary gridded data obtained from remote sensing technologies (e.g. Light Detection And Ranging, lidar).

Another possible explanation for the discrepancies stems from the complexity of the actual flow fields at the intersections, involving different flow regimes, hydraulic jumps and waves as described in the literature cited in the Introduction section. Here, it is, however, difficult to identify which intersection is responsible for the main discrepancies as they all interact with each other and the experimental flow partition between the streets is only available at the downstream end of each street and not between all the intersections.

A closer look at the computed results reveals that the higher the total discharge, the higher the outflow from the widest straight streets 4 and $C(+0.6$ and $+1.75 \%$ respectively for a total inflow varying from 10 to $\left.100 \mathrm{~m}^{3} \mathrm{~h}^{-1}\right)$. In the streets with the lowest outflow discharges $(1-3,5-7, \mathrm{D}$, $\mathrm{E}$ and $\mathrm{G})$, the computed variation is opposite: minus $0.4 \%$ on average. In contrast, the variations observed experimentally are not monotonous as the numerical results are (e.g. in streets 1, 3, 4 and C). 

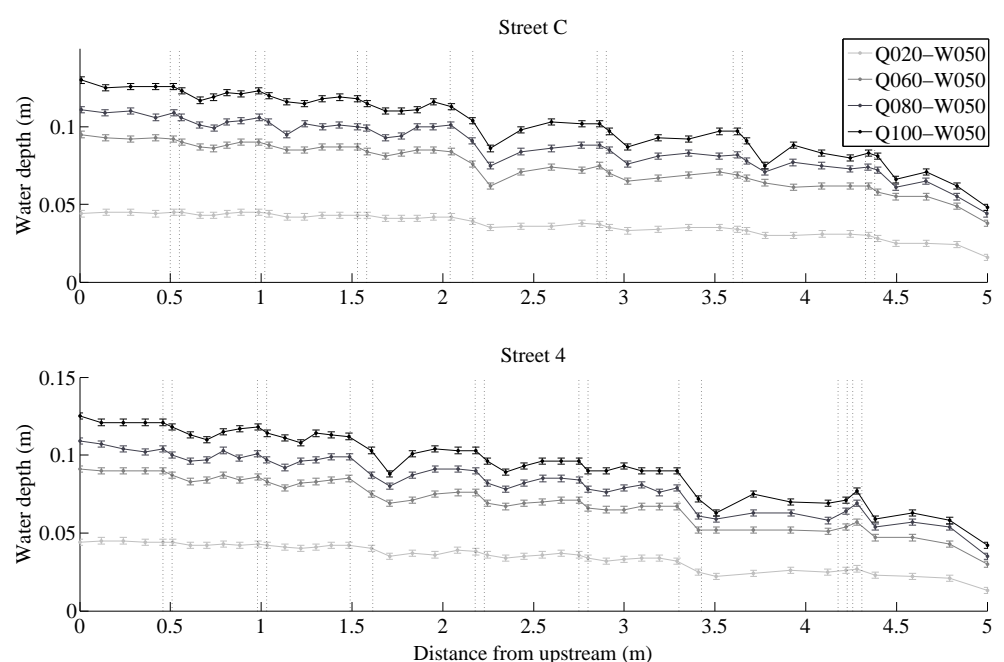

Figure 4. Observed water depths in streets $\mathrm{C}$ and 4 for inflow discharges varying between 20 and $100 \mathrm{~m}^{3} \mathrm{~s}^{-1}$. Dashed vertical lines indicate the intersections.

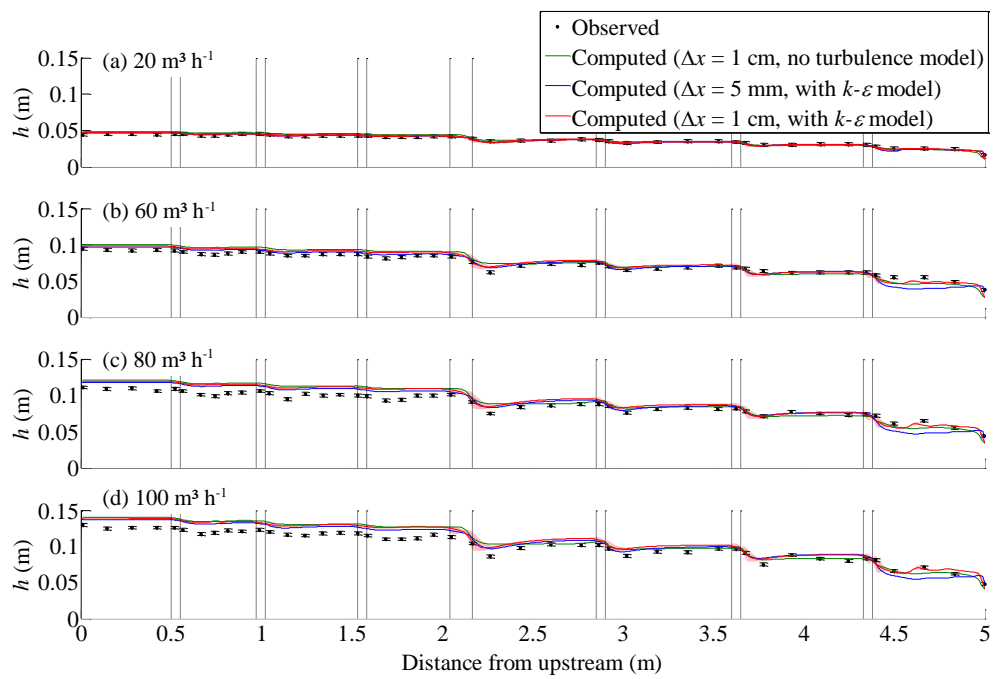

Figure 5. Observed and computed water depths $h$ for inflow discharges varying between 20 and $100 \mathrm{~m}^{3} \mathrm{~h}^{-1}$ in street $\mathrm{C}$. The shaded area represents the range of variation in the crosswise direction of the computed water depths $(\Delta x=1 \mathrm{~cm}$, with $k-\varepsilon$ model).

\subsubsection{Water depths at the district level}

For four different inflow discharges, maps of the observed and computed water depth distributions over the whole district are provided as Supplement 2, both in absolute values and scaled by the district-averaged water depth (Figs. S1 and S2). The observed district-averaged water depth is shown to increase from 3.4 up to $9.0 \mathrm{~cm}$ when the inflow discharge is varied from 20 to $100 \mathrm{~m}^{3} \mathrm{~h}^{-1}$ (Table 2). The relative distribution of water depths across the district is hardly affected by the total inflow, as shown in Fig. S1.

The computed values are in excellent agreement with the observations for the lowest inflow discharge; but they deviate by about $11 \%$ for the highest inflow discharge $\left(100 \mathrm{~m}^{3} \mathrm{~h}^{-1}\right.$,
Table 2). For this discharge, the observed maximum water depth is $14.1 \mathrm{~cm}$, while the corresponding computed value reaches $15.72 \mathrm{~cm}$. This also hints that the Cartesian grid may explain part of the discrepancies, as this mesh effect is expected to lead to greater overestimations as the flow velocity increases.

\subsubsection{Water depths at the street level}

The profiles of observed water depths along the centreline of the streets are displayed in Fig. 4 for the two widest streets (4 and C). The most significant streamwise variations in the water depths take place locally, in the vicinity and immediately downstream of the intersections, particularly close to the intersections of two wide streets such as streets $\mathrm{C}$ and 4 , 


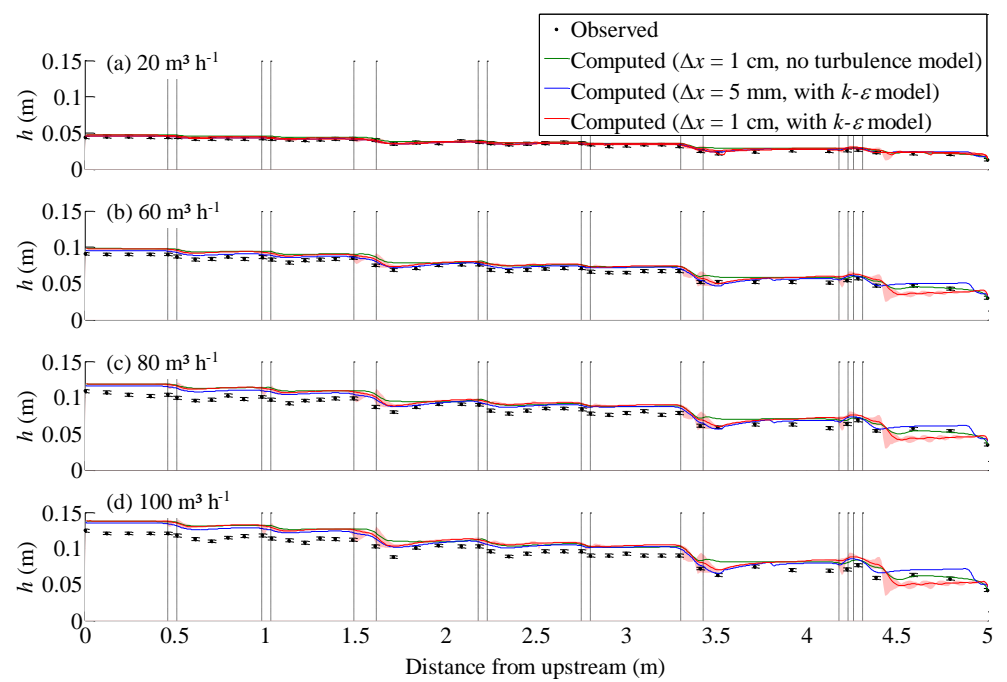

Figure 6. Observed and computed water depths $h$ for inflow discharges varying between 20 and $100 \mathrm{~m}^{3} \mathrm{~h}^{-1}$ in street 4 . The shaded area ( represents the range of variation in the crosswise direction of the computed water depths $(\Delta x=1 \mathrm{~cm}$, with $k-\varepsilon$ model).

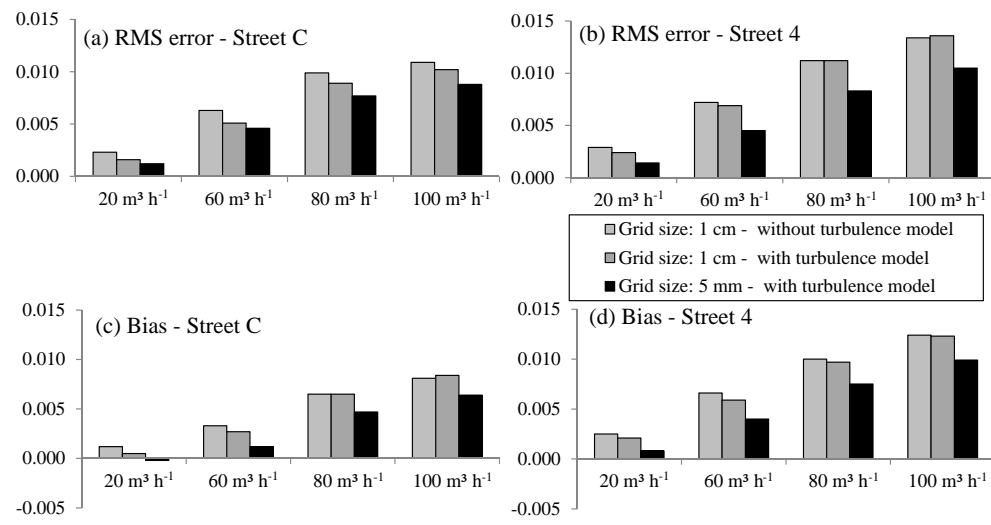

Figure 7. Bias and root mean square error (RMSE) on the computed water depths in streets C and 4.

Table 2. District-averaged water depths for inflow discharges between 20 and $100 \mathrm{~m}^{3} \mathrm{~h}^{-1}$.

\begin{tabular}{lccr}
\hline Test ID & $\begin{array}{c}\text { Observed } \\
(\mathrm{cm})\end{array}$ & $\begin{array}{c}\text { Computed } \\
(\mathrm{cm})\end{array}$ & $\begin{array}{r}\text { Relative } \\
\text { difference }\end{array}$ \\
\hline Q020-W050 & 3.37 & 3.41 & $+1 \%$ \\
Q060-W050 & 6.78 & 7.04 & $+4 \%$ \\
Q080-W050 & 8.25 & 8.55 & $+4 \%$ \\
Q100-W050 & 8.98 & 9.94 & $+11 \%$ \\
\hline
\end{tabular}

or streets 4 and F. In contrast, between the intersections, the water depths remain fairly constant. Therefore, friction is expected to play a minor part, as discussed in Sect. 3.2.

As shown in Figs. 5 and 6, the computed results reproduce the main features of the water depth profiles qualitatively, which are characterized by sudden drops near the intersections and remain almost constant between the intersec- tions. From a quantitative perspective, the computed results are relatively accurate for the lowest discharge $\left(20 \mathrm{~m}^{3} \mathrm{~h}^{-1}\right)$; but they tend to deviate from the observations as the inflow discharge is increased. This is also highlighted in Fig. 7a and $b$, which shows an increase in the root mean square error (RMSE) from about $1-2 \mathrm{~mm}$ up to $1-1.4 \mathrm{~cm}$ as the inflow discharge rises from 20 up to $100 \mathrm{~m}^{3} \mathrm{~h}^{-1}$. As shown by the sign of the bias in Fig. 7c and d, all significant deviations correspond to overestimations of the water depths. Again, this trend is consistent with an extra flow resistance induced by the Cartesian grid when the obstacles are not aligned with the grid.

Although experimental measurements of water depths could only be performed along the streets' centreline, we used the numerical simulations to appreciate to which extent the flow depth varies within a cross section. As shown by the shaded area ( $\square$ ) in Figs. 5 and 6, significant crosswise variations in the flow depths are only obtained in the near-field of 
the street intersections, which is consistent with the presence of flow structures such as recirculations and vena contracta downstream of the intersections.

\subsection{Sensitivity analysis of the numerical results}

To appreciate the sensitivity of the results to different modelling choices, a sensitivity analysis was performed to investigate the influence of roughness, mesh refinement and the turbulence model.

\subsubsection{Roughness parameter}

The reference simulations were carried out with a roughness height equal to zero $(k=0 \mathrm{~mm})$ as the experimental model was in Plexiglas, which is similar to glass $(k \sim 0.01 \mathrm{~mm})$ in terms of roughness characteristics. The simulations were also repeated with a roughness height $k=1 \mathrm{~mm}$, which we considered as an upper bound of the range of possible roughness characteristics of the experimental set-up. Testing higher values of $k$ was deemed unrealistic.

The distribution of the outflow discharges between the different streets remains virtually unchanged when the roughness height is varied between 0 and $1 \mathrm{~mm}$ (Fig. S3). For $k=0 \mathrm{~mm}$, the RMSE of the computed outflow discharges ranges between 1.7 and $2.0 \%$ of the inflow discharge, while it ranges between 1.7 and $1.9 \%$ when the roughness height is increased up to $1 \mathrm{~mm}$ (Table S2). This confirms the slight influence of the roughness parameter on the computational results, as anticipated from the water profiles measured in the main streets of the experimental model (Fig. 4). Whether this finding also applies on the prototype scale is discussed in Sect. 5.2.

\subsubsection{Grid refinement}

The influence of the mesh refinement on the results was tested by using cell sizes of $1 \mathrm{~cm}$ and 5 and $2.5 \mathrm{~mm}$. For total inflows of $10,20,60,80$ and $100 \mathrm{~m}^{3} \mathrm{~h}^{-1}$, Fig. 8 compares the computed and measured outflow discharges in each street. Most points fall within the $\pm 15 \%$ range in terms of relative error street by street. For a grid spacing of $1 \mathrm{~cm}$, the root mean square error of the outflow discharges lies between 1.7 and $2.0 \%$ of the total inflow (Table 3). Shifting from a $1 \mathrm{~cm}$ grid to a $5 \mathrm{~mm}$ grid leads to a reduction in the root mean square error of the discharges to $1.1-1.5 \%$. Figure 8 also shows that the discharge partitions in the widest streets are substantially improved when the cell size is reduced to $5 \mathrm{~mm}$.

For a total inflow of $20 \mathrm{~m}^{3} \mathrm{~h}^{-1}$, the computation was also performed with a $2.5 \mathrm{~mm}$ grid; but the change in the root mean square is slight (below $0.1 \%$ ). Thus, grid refinement to $2.5 \mathrm{~mm}$ does not lead to a significantly better fit of the model predictions. This suggests that the numerical discretization with a cell size of $5 \mathrm{~mm}$ is converged in the sense of a grid convergence analysis (Roache, 1994).
The sensitivity of the computed water depths with respect to the grid resolution was also assessed. As shown in Fig. 7, refining the cell size to $5 \mathrm{~mm}$ instead of $1 \mathrm{~cm}$ reduces the RMSE and the bias by about $20 \%$ in the case of the highest inflow discharges, for which these errors are maximum. This reduction is in agreement with a decreased influence of the staircase approximation of the obstacles' geometry when a finer grid resolution is used.

Changing the grid size also leads to local changes in the flow pattern. As an example, Fig. 9 shows the details of the flow field near the downstream end of street 4 in the case of test Q100-W050 computed with cell sizes of $1 \mathrm{~cm}$ and $5 \mathrm{~mm}$. The discretization of the model geometry on a Cartesian grid induces local discontinuities in the street widths as long as these streets are not perfectly aligned with the grid, as is the case here particularly because the "as-built" coordinates of the obstacles were used. These sudden changes in the street width lead in some cases to the development of flow structures (such as cross waves), which as a matter of fact are mesh-dependent (Fig. 9a and b). Their impact remains, however, very limited further upstream in the domain, where the flow patterns are extremely similar for the two grid sizes (Fig. 9).

Despite the better results obtained with the cell size of $5 \mathrm{~mm}$, in most of the simulations performed hereafter, the $1 \mathrm{~cm}$ grid was kept nonetheless because in our opinion this choice is the most consistent with grid refinements reasonably accessible for inundation mapping in practice. It corresponds indeed to five cells over the width of the narrow streets and about 12 cells over the width of the wide streets (4, C and F, as detailed in Table 4). At the field scale, it leads to a grid spacing of $2 \mathrm{~m}$ (Sect. 5.2). Using finer cells (5 or $2.5 \mathrm{~mm}$ ) would not be realistic compared to typical grid refinements used for real-world flood hazard mapping (e.g. Bazin, 2013). The $1 \mathrm{~cm}$ grid may also be considered as a reasonable trade-off between accuracy and computational burden since opting for the $5 \mathrm{~mm}$ grid would also decrease the time step by a factor of 2 due to the Courant-FriedrichsLewy (CFL) stability condition (e.g. Bates et al., 2010) and, therefore, it would lead to an increase in the computational cost by almost 1 order of magnitude $(\sim 8)$ for a moderate reduction in the errors.

\subsubsection{Turbulence model}

Most flood hazard mapping in practice is conducted with depth-averaged models which do not incorporate a proper turbulence model, apart from a friction term which lumps all dissipative effects. Here, we specifically tested the influence of activating the $k-\varepsilon$ turbulence model, which is available in WOLF 2-D, or not.

The computations reveal that the turbulence model hardly influences the outflow discharges. This result applies when the outflows are examined by face (Fig. 2) and also when they are disaggregated at the street level (Fig. 8). At the face level, 
Table 3. Root mean square error of the outflow discharges in each street (expressed in percentage of the total inflow), as a function of the total inflow and the modelling characteristics.

\begin{tabular}{llccccc}
\hline $\begin{array}{l}\text { Grid } \\
\text { spacing }\end{array}$ & $\begin{array}{l}\text { Turbulence } \\
\text { model }\end{array}$ & $10 \mathrm{~m}^{3} \mathrm{~h}^{-1}$ & $20 \mathrm{~m}^{3} \mathrm{~h}^{-1}$ & $60 \mathrm{~m}^{3} \mathrm{~h}^{-1}$ & $80 \mathrm{~m}^{3} \mathrm{~h}^{-1}$ & $100 \mathrm{~m}^{3} \mathrm{~h}^{-1}$ \\
\hline $1 \mathrm{~cm}$ & None & $2.0 \%$ & $1.8 \%$ & $1.9 \%$ & $1.9 \%$ & $2.0 \%$ \\
$1 \mathrm{~cm}$ & $k-\varepsilon$ & $1.9 \%$ & $1.7 \%$ & $1.8 \%$ & $1.9 \%$ & $2.0 \%$ \\
$5 \mathrm{~mm}$ & None & $1.4 \%$ & $1.2 \%$ & $1.4 \%$ & $1.4 \%$ & $1.5 \%$ \\
$5 \mathrm{~mm}$ & $k-\varepsilon$ & $1.3 \%$ & $1.1 \%$ & $1.3 \%$ & $1.4 \%$ & $1.5 \%$ \\
$2.5 \mathrm{~mm}$ & $k-\varepsilon$ & & $1.2 \%$ & & & \\
\hline
\end{tabular}
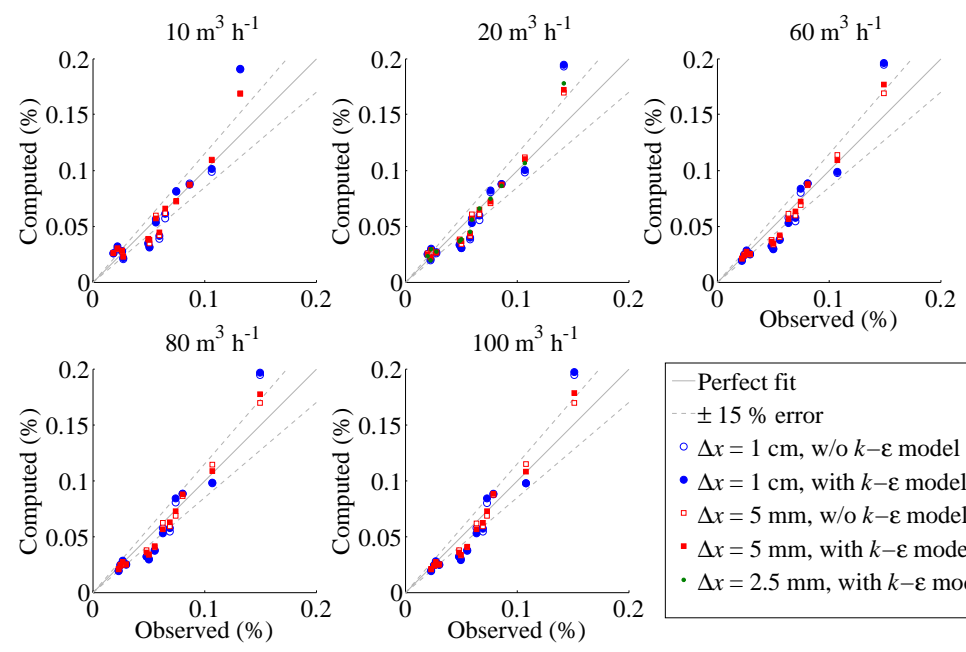

$$
\begin{aligned}
& \text { - Perfect fit } \\
& \pm 15 \% \text { error } \\
& -\Delta x=1 \mathrm{~cm} \text {, w/o } k-\varepsilon \text { model } \\
& -\Delta x=1 \mathrm{~cm} \text {, with } k-\varepsilon \text { model } \\
& -\Delta x=5 \mathrm{~mm}, \text { w/o } k-\varepsilon \text { model } \\
& -\Delta x=5 \mathrm{~mm}, \text { with } k-\varepsilon \text { model } \\
& \cdot \Delta x=2.5 \mathrm{~mm}, \text { with } k-\varepsilon \text { model }
\end{aligned}
$$

Figure 8. Computed vs. measured outflow discharges in each street (in percent of the total inflow) considering different cell sizes $\Delta x$ in the computation, with or without the turbulence model.

Table 4. Considered grid sizes and corresponding resolution obtained on the field scale.

\begin{tabular}{lrrl}
\hline $\begin{array}{l}\text { Grid } \\
\text { spacing } \\
\text { (laboratory } \\
\text { scale) }\end{array}$ & $\begin{array}{r}\text { Grid } \\
\text { spacing } \\
\text { upscaled } \\
\text { on the } \\
\text { field scale }\end{array}$ & $\begin{array}{r}\text { Number } \\
\text { of cells } \\
\text { over the } \\
\text { width of } \\
\text { narrow } \\
\text { streets }\end{array}$ & $\begin{array}{l}\text { Number } \\
\text { of cells } \\
\text { over the } \\
\text { width of } \\
\text { wide } \\
\text { streets }\end{array}$ \\
\hline $1 \mathrm{~cm}$ & $2 \mathrm{~m}$ & 5 & 12.5 \\
$5 \mathrm{~mm}$ & $1 \mathrm{~m}$ & 10 & 25 \\
$2.5 \mathrm{~mm}$ & $0.5 \mathrm{~m}$ & 20 & 50 \\
\hline
\end{tabular}

switching the turbulence model on or off induces variations in the outflow discharge not exceeding $1.5 \%$ (Fig. 2). At the street level, the relative differences may reach $2 \%$; but these differences are much lower than those observed when changing the grid size from $1 \mathrm{~cm}$ to $5 \mathrm{~mm}$. For the whole range of considered total inflows, the influence of the turbulence model on the root mean square error of the outflow partition between the streets is of the order of $0.1 \%$ of the total inflow, both for the $1 \mathrm{~cm}$ grid and for the $5 \mathrm{~mm}$ grid (Tables 3 and S2). This remains about 5 times lower than the influence of the grid size, but similar to the influence of the roughness parameter $k$.

As regards the influence of the turbulence model on the computed water depths, the simulations without the turbulence model perform slightly worse than when the turbulence model is used (Figs. 5 and 6). This is also confirmed by an increase in the RMSE and in the bias for most considered discharges (Fig. 7).

Like the cell size, the turbulence model also has a substantial influence on some local features of the flow field. For tests Q020-W050 and Q100-W050, Figure 10 shows the computed velocity fields. As also noticed in the experiments, flow recirculations and vena contracta are observed downstream of the intersections. This is consistent with flow descriptions available in literature (e.g. Weber et al., 2001; Neary et al., 1999) and with the significant crosswise variations in the water depths shown in Figs. 5 and 6. Figure 10 also reveals that the recirculation lengths in the streets differ significantly between the results computed with and without the turbulence model. In the former case, the recirculation length $R_{T}$ is of the order of 2 to 4 times the street width (Figure 10a and c) and is in overall agreement with results of de- 


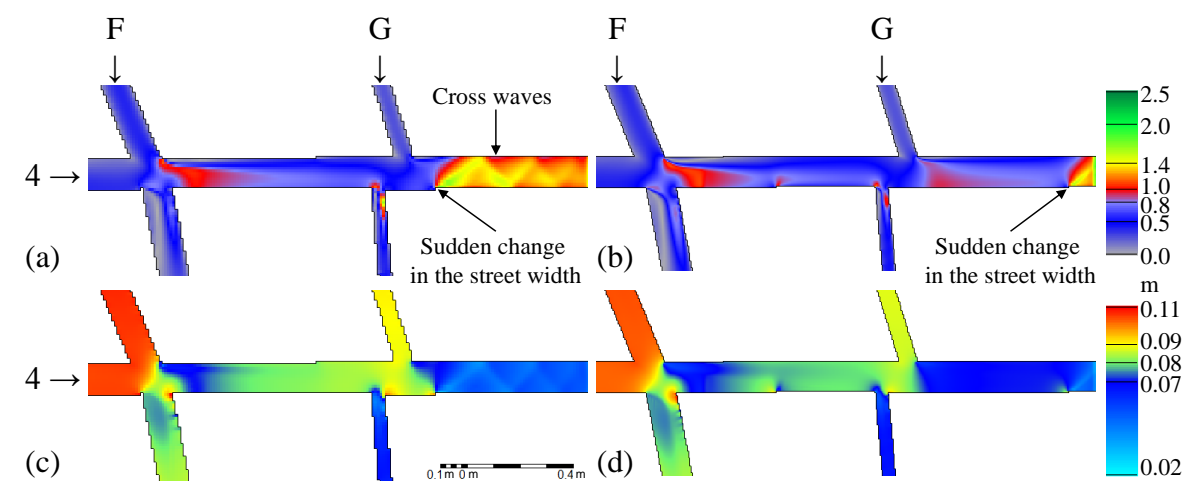

Figure 9. Froude numbers $(\mathbf{a}, \mathbf{b})$ and water depths $(\mathbf{c}, \mathbf{d})$ computed for test Q100-W050 and cell sizes of $1 \mathrm{~cm}(\mathbf{a}, \mathbf{c})$ and $5 \mathrm{~mm}(\mathbf{b}, \mathbf{d})$.
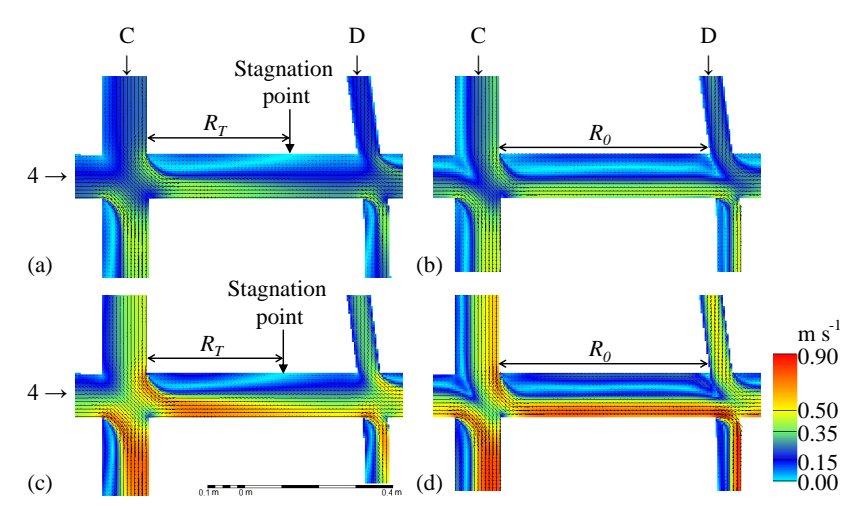

Figure 10. Velocity fields computed with $(\mathbf{a}, \mathbf{c})$ and without $(\mathbf{b}, \mathbf{d})$ the turbulence model for tests Q020-W050 (a, b) and Q100W050 (c, d). Grid size: $5 \mathrm{~mm}$.

tailed 3-D simulations performed by Li and Zeng (2010), also in terms of recirculation width. In contrast, simulations without the turbulence model lead to recirculation zones which tend to preserve a constant width over the whole length of the streets (Fig. 10b and d) and their overall shape looks less realistic, particularly in comparison with the results of $\mathrm{Li}$ and Zeng (2010). This results from the hardly dissipative nature of the flow model without the turbulence model.

Such changes in the flow structure between simulations with and without the turbulence model may be related to local variations in the discharge partition. For test Q100W050, Fig. 11 details the flow field at the intersection between streets 4 and F. Besides variations in the recirculation lengths as already highlighted in Fig. 10, Fig. 11 also reveals a change in the recirculation width in the southern branch. While the width reaches 6-7 cm when the turbulence model is used (Fig. 11a and c), it is restricted to $3-4 \mathrm{~cm}$ without the turbulence model. As a result, the share of discharge maintained in street 4 in the simulation with the turbulence model is about $9 \%$ higher than in the simulation without the turbulence model. This figure was obtained with a grid size of $5 \mathrm{~mm}$, while the change is estimated at $6 \%$ based on the

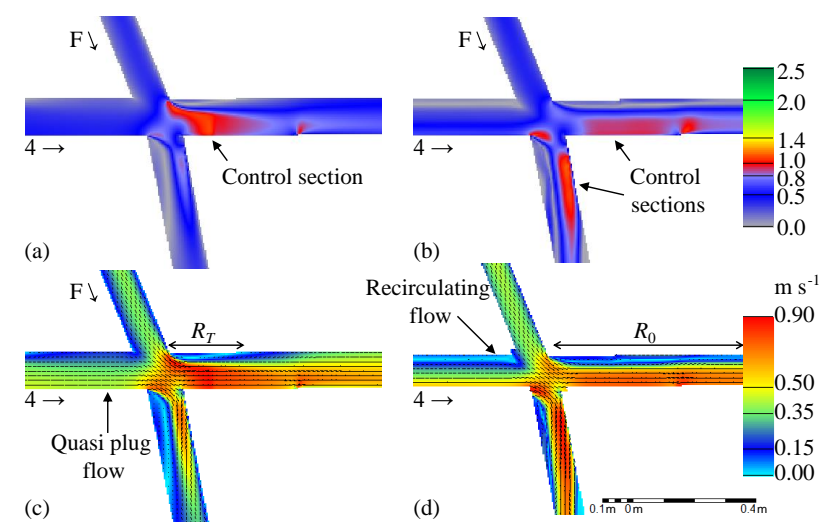

Figure 11. Froude numbers $(\mathbf{a}, \mathbf{b})$ and velocity fields $(\mathbf{c}, \mathbf{d})$ computed with $(\mathbf{a}, \mathbf{c})$ and without $(\mathbf{b}, \mathbf{d})$ the turbulence model for test Q100-W050 (c, d). Grid size: 5 mm.

$1 \mathrm{~cm}$ grid size. In turn, this change in the flow partition alters the shape of the control sections in the downstream part of street 4 (Fig. 11a and b), and also the overall distribution of water depths. Figure 11a and $\mathrm{b}$ also highlight the presence of control sections in the vena contracta, which is consistent with e.g. Fig. 5 in Rivière et al. (2014).

In the following, the turbulence model has been systematically used due to the higher realism that it provides for simulating the flow processes.

\section{Influence of inflow partition}

A distinctive feature of the present experimental set-up is that it enables the partition of inflow to be varied continuously between the west and the north faces. For a total inflow discharge of $60 \mathrm{~m}^{3} \mathrm{~h}^{-1}$, the portion of inflow through the west face (noted $\varphi_{\text {west }}$ ) was varied between 0 and $100 \%$ by steps of $10 \%$ (Table 1). In these tests, only the outflow discharges were measured and not the water depths.

As shown in Fig. 12, the observed outflow discharge through the east face (noted $\varphi_{\text {east }}$ ) decreases as $\varphi_{\text {west }}$ is re- 


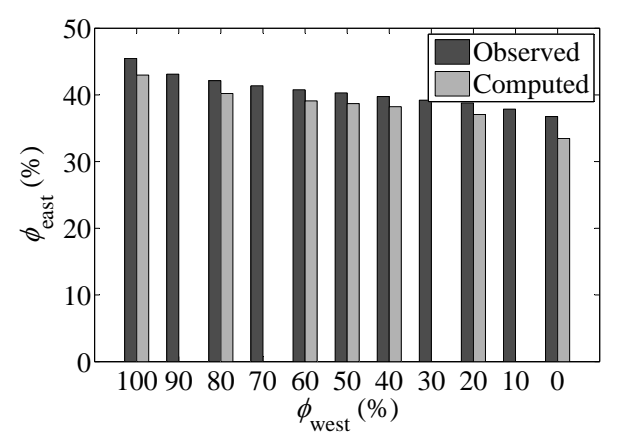

Figure 12. Observed and computed portions of outflow discharge through the east face $\left(\varphi_{\text {east }}\right)$ when the inflow through the north face $\left(\varphi_{\text {north }}\right)$ is varied from 0 up to $100 \%$.

duced. However, for $\varphi_{\text {west }}$ varying from 100 down to $0 \%$, the observed value of $\varphi_{\text {east }}$ is only reduced from 45 to $37 \%$. So, the scaled sensitivity of $\varphi_{\text {east }}$ with respect to $\varphi_{\text {west }}$ is lower than 0.1 , reflecting the ability of the multiple obstacles faced by the flow within the district to redistribute the outflow discharge at the face level almost irrespective of the upstream flow partition.

The computed outflow discharges through the east face slightly underestimate the observed values (by 1.5 to $3.3 \%$ ) but they show a similar trend as the observations: $\varphi_{\text {east }}$ drops by $10 \%$ (from 43 to $33 \%$ ) when $\varphi_{\text {west }}$ is reduced from 100 to $0 \%$.

The distribution of the outflow discharges at the street level is shown in Fig. 13. Three groups of streets may be distinguished.

- In streets 1 to 4, which end up on the eastern face, the outflow discharge declines steadily as $\varphi_{\text {west }}$ is increased.

- Contrarily, the outflow discharges rise in street $\mathrm{C}$ and to a lesser extent in streets A, B, D and F, which all end up on the southern face.

- The other streets are less significantly influenced by the partition of outflow discharge.

Figure 14 compares the computed results to the observations. Consistently with the results shown in Fig. 3, the computations overestimate the outflow discharges in the widest streets (by about $20 \%$ in streets $\mathrm{C}$ and 4 ), while they underestimate the outflow discharges in most other streets. This aspect is shown here to remain similar independently of the partition of the inflow discharge (Fig. 14). Despite the overestimation of the outflow discharge in streets $\mathrm{C}$ and 4 , the relative influence of a change in $\varphi_{\text {west }}$ is fairly well reproduced by the numerical model.

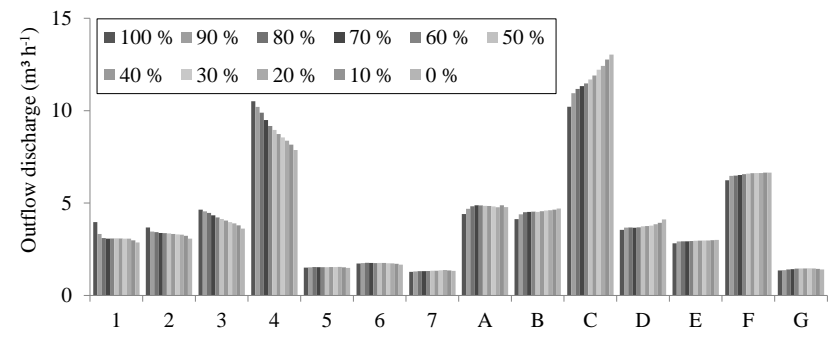

Figure 13. Observed outflow discharges in each street for when the inflow through the west face $\left(\varphi_{\text {west }}\right)$ is varied between 100 and $0 \%$.

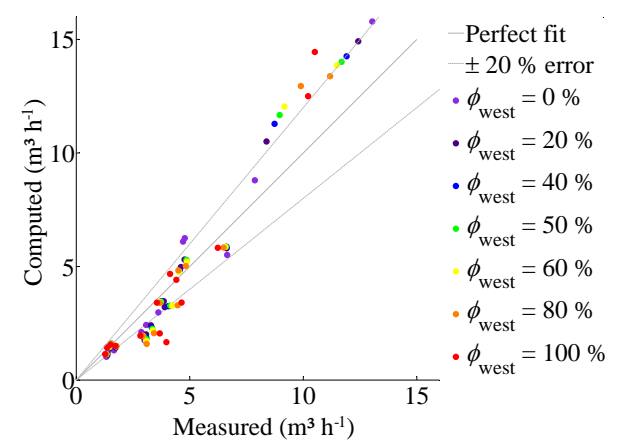

Figure 14. Computed vs. observed outflow discharges in each street for different partitions of the inflow discharge between the west and north faces.

\section{Discussion}

\subsection{Outflow partition between the faces and its independence from the inflow discharge}

As detailed in Sect. 3.1.1, the experimental observations indicate that, for $\varphi_{\text {west }}=50 \%$, the outflow through the east face is about $40 \%$ of the total inflow, while the outflow through the south face is $60 \%$ of the total inflow. In addition, the observed outflow partition remains virtually independent of the total inflow discharge. These experimental findings were also confirmed by the 2-D numerical simulations (Fig. 2). In Sect. 3.1.1, we attribute this distinctive flow partition to the higher total flow width available in the north-south direction compared to the west-east direction.

To test this hypothesis of "attraction" effect of the wider streets independently of the total inflow, we undertook additional simulations corresponding to a single "equivalent" four-branch intersection, with the north-south and west-east streets widths respectively equal to 0.5 and $0.425 \mathrm{~m}$. These widths mimic the cumulative street widths in the north-south and the west-east directions in the experimental model (respectively equal to 0.5 and $0.425 \mathrm{~m}$ ). We performed the simulations for the two extreme discharges (20 and $100 \mathrm{~m}^{3} \mathrm{~h}^{-1}$ ), with equal inflow partition between the west and north faces $\left(\varphi_{\text {west }}=50 \%\right)$ and assuming a smooth bottom $(k=0 \mathrm{~m})$. Free-flow boundary conditions were prescribed at the down- 
Table 5. Characteristic Reynolds number $R$, roughness height $k$ and Darcy-Weisbach coefficient $f$ on the laboratory model scale and at the prototype scale (real-world) as a function of the horizontal and vertical magnification factors $e_{\mathrm{H}}$ and $e_{\mathrm{V}}$.

\begin{tabular}{lllll}
\hline & Laboratory model & \multicolumn{2}{c}{ Prototype 1 } & Prototype 2 \\
& & &
\end{tabular}

stream end of each street, located at a long distance downstream of the crossroad ( 8 times the street width). We used the finest grid spacing considered in the paper $(\Delta x=2.5 \mathrm{~mm}$, Sect. 3.2.2) and we tested the computations with and without activation of the turbulence model (Sect. 3.2.3). For both inflow discharges $\left(20\right.$ and $100 \mathrm{~m}^{3} \mathrm{~h}^{-1}$ ), the computed results reveal a partition of the outflow discharge proportional to the street widths (54\% vs. $46 \%$ ). The same results were obtained with and without activation of the turbulence model. It seems, therefore, that the geometric effect resulting from the difference in the cumulative street widths in the north-south and west-east directions acts similarly over the whole range of considered inflow discharges $\left(20\right.$ and $\left.100 \mathrm{~m}^{3} \mathrm{~h}^{-1}\right)$.

Nonetheless, this geometric effect only partly explains the difference in the experimentally observed outflow discharges through the south and east faces ( $60 \%$ vs. $40 \%$ ). We attribute the remaining difference to (i) the spatial distribution of the wider streets within the scale model, and (ii) the inclination of several streets. These two effects are not properly reflected in the single "equivalent" intersection considered here; but they are expected to further amplify the difference in the outflow discharges between the north-south and the west-east directions.

\subsection{Upscaling}

The simulations presented in Sect. 3.2 have revealed that the values of the roughness parameter $k$ and the turbulence model have little influence on the computed discharge partitions and water depths in the laboratory model. We discuss here to which extent these conclusions remain valid for real-world applications, i.e. on a prototype scale. Assuming Froude similarity, the simulations were repeated on the prototype scale following three different procedures, referred to as Prototype 1 to 3 in Table 5.
First, all geometric characteristics of the laboratory model were magnified by a factor $e_{\mathrm{H}}=e_{\mathrm{V}}=200$, leading to street widths of the order of 10 to $25 \mathrm{~m}$ (Prototype 1 in Table 5). Using Colebrook friction formula (or the Moody diagram), the roughness height $k$ was selected so as to preserve approximately the same Darcy-Weisbach coefficient $(f \sim 0.02)$ as on the scale of the laboratory model. Note that $k$ does not simply scale with the water depth since the laboratory model operates in the transition zone $\left(R \sim 10^{4}-10^{5}\right)$, while the flow is fully turbulent on the prototype scale $\left(R \sim 10^{7}-10^{8}\right)$. In the end, the simulations results obtained on the prototype scale were divided by the factor $e_{\mathrm{H}}=e_{\mathrm{V}}=200$ to enable direct comparisons with the results on the scale of the laboratory model. As shown in Fig. S4, the two sets of results match almost perfectly. This agreement was obtained for roughness heights on the prototype scale between zero and up to $k=5 \mathrm{~cm}$, with and without the turbulence model, confirming that in Prototype 1 the value of $k$ and the turbulence model have little influence on the results, consistent with the findings on the laboratory scale.

However, Prototype 1 is hardly realistic in terms of height to width ratio in the streets. Most real-world urban floods are characterized by much smaller water depths compared to the widths of the streets. Therefore, upscaling of the laboratory model was also performed, assuming a distorted model with a horizontal scale factor $e_{\mathrm{H}}=200$ and a vertical scale factor $e_{\mathrm{V}}=20$ (Prototype 2 in Table 5). In Prototype 2, a roughness height of the order $5 \times 10^{-3} \mathrm{~m}$ leads to similar values of the Darcy-Weisbach coefficient as on the laboratory scale. Nonetheless, as a result of the smaller water depths, the relative effect of friction becomes higher than in the experimental configuration, as shown in Fig. S4. Finally, we consider that a reasonable roughness height characterizing urbanized floodplains is of the order of $\sim 0.1 \mathrm{~m}$ (Prototype 3 in Table 5) instead of $5 \times 10^{-3} \mathrm{~m}$. As shown in Fig. S4, this further emphasizes the influence of friction and dissipation on the flow, 
which is not properly reflected in the experimental model made of smooth boundaries (Plexiglass).

\subsection{Porosity-based approach}

In Sect. 3.1, the discrepancies between computed and observed results were, to a large extent, attributed to the intrinsic limitations of Cartesian grids to reproduce oblique boundaries. To investigate this effect further, we tested an extended shallow-water model involving anisotropic porosity parameters to improve the representation of complex boundaries in a Cartesian grid framework. This approach is similar to the "cut-cell" technique (An et al., 2015; Causon et al., 2000; Kim and Cho, 2011).

We used two types of porosity parameters (Fig. 15). First, a "storage porosity" $\phi$ is defined for each cell $(i, j)$ of the two-dimensional grid. It represents the fraction of the cell surface which is actually available to store water despite the presence of solid obstacles (i.e. the void fraction in the cell). Similarly, a "conveyance porosity" $\psi$ is defined at each cell interface to reflect the blockage effect of the solid obstacles. It quantifies the fraction of the face length which remains available for exchanges with the neighbouring cells. The resulting shallow-water equations with porosity are formally equivalent to those used by Sanders et al. (2008) and Kim et al. (2015).

The partition of outflow discharges at the street level has been computed using the model with porosity. The results are displayed in Fig. 16, which should be compared to Fig. 3 . While the outflows from streets 4 and $\mathrm{C}$ are overestimated by $10-30 \%$ when the standard shallow-water model is used, this discrepancy is reduced here to around $10 \%$. Similarly, the outflow discharges through the narrower streets 1-3 and DF were significantly underestimated by the standard model, whereas these outflows are now predicted with an error not exceeding $8 \%$. This leads to a root mean square error of the outflow discharge which is reduced from 19 to $6.6 \%$ as a result of using the shallow-water equations with porosity.

The model based on anisotropic porosity parameters described here is certainly a viable approach for practical applications. For the considered experiments, all porosity parameters were deduced directly from geometric data and there was no calibration of these porosity parameters: $\phi$ is simply the void fraction in the cell, while $\psi$ is given by the fraction of each cell interface which is not blocked by obstacles. The same approach may apply for real-world cases, for which a digital terrain model is used to describe the topography and vector data are available to locate the position of the buildings. Among others, Schubert and Sanders (2012) applied such a technique ("building porosity" approach) to simulate the Baldwin Hills urban dam break scenario. Sanders et al. (2008) applied a similar model to the Toce Valley flash flood, using a so-called "gap-conforming" mesh.

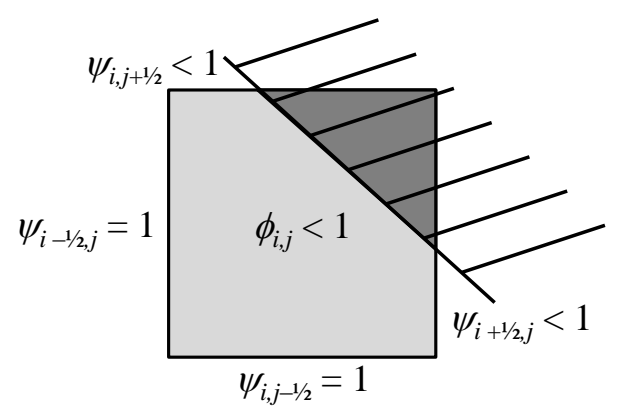

Figure 15. Storage porosity $\phi$ defined for each cell $(i, j)$ of the two-dimensional grid and conveyance porosities $\psi$ defined at the four faces of each grid cell.

\subsection{Unsteady effects}

The present study relies on steady-state experiments and numerical simulations, while real-world floods are intrinsically transient. Whether a real flood wave can be approximated as a succession of steady states depends on the timescales of interest. Therefore, we undertook extra simulations in unsteady mode, with the purpose of identifying a characteristic timescale of the urban district considered here.

The initial condition corresponds to virtually no water in the model (initial water depth $=1 \mathrm{~mm}$ ) and no flow. At the initial time, the inflow was suddenly raised to its maximum value upstream of each street. We considered inflow discharges of $20,60,80$ and $100 \mathrm{~m}^{3} \mathrm{~h}^{-1}$, as well as the following parameters: $\varphi_{\text {west }}=50 \%$, no turbulence model, smooth bottom $(k=0 \mathrm{~m})$ and $\Delta x=1 \mathrm{~cm}$.

Time series of computed water depths in the centre of the most upstream intersection (i.e. between streets 1 and A) and between the two wide streets 4 and $\mathrm{C}$ are displayed in Fig. 17. They reveal that the time necessary for reaching a steady state is of the order of 30-60 s on the scale of the laboratory model.

The scale factor for time is given by the ratio between the scale factor for horizontal lengths $\left(1 / e_{\mathrm{H}}\right)$ and the scale factor for velocity. The latter is the square root of the scale factor for vertical dimensions $\left(1 / e_{\mathrm{V}}\right)$, consistently with the Froude similarity adopted here (Sect. 5.2). Hence, the characteristic times obtained on the scale of the laboratory model must be magnified by $e_{\mathrm{H}} /\left(e_{\mathrm{V}}\right)^{0.5}$ to obtain the corresponding characteristic times on the prototype scale.

- For Prototype 1, this leads to a magnification factor of $200 / 200^{0.5}$, and hence to a characteristic time of the order of $7-14 \mathrm{~min}$.

- For the more realistic Prototypes 2 and 3, a magnification factor of $200 / 20^{0.5}$ is obtained, which leads to a characteristic time of the order of $20-45 \mathrm{~min}$.

In conclusion, the observations of the present research remain valid, provided that the considered flood events remain 


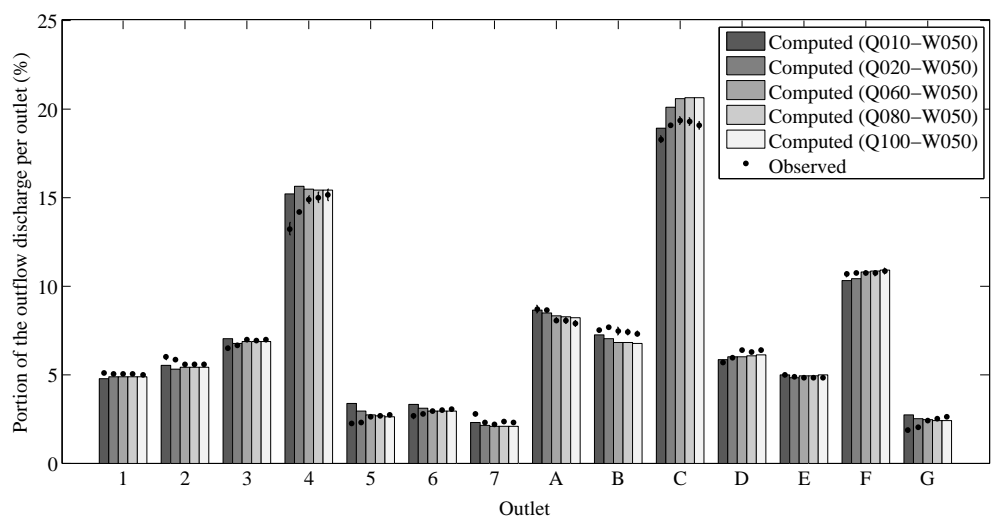

Figure 16. Contributions of each street to the total outflow discharge for five different inflow discharges: observations vs. results computed with the shallow-water equations with porosity.
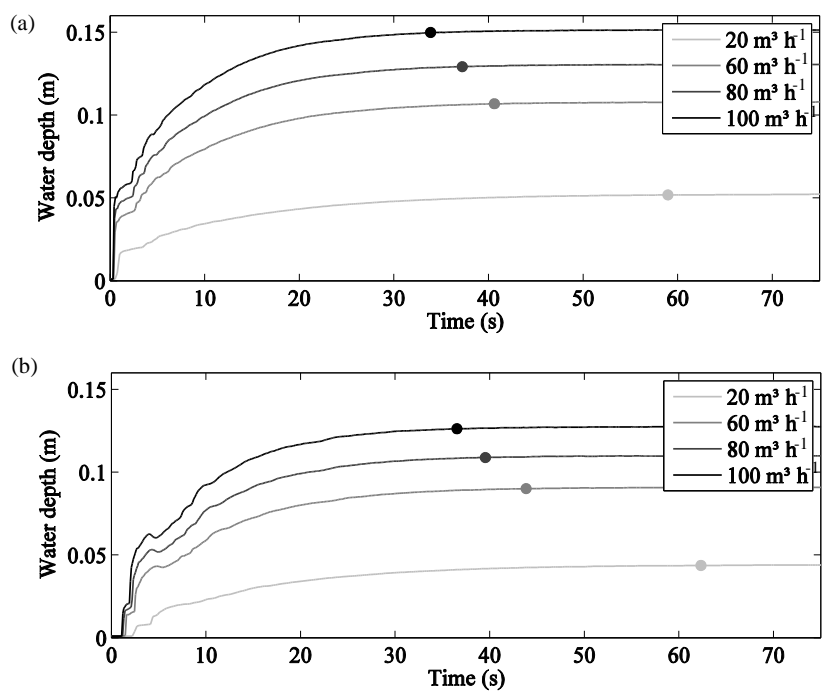

Figure 17. Computed water depths in the unsteady simulations, at the intersections (a) between streets 1 and $\mathrm{A}$, and (b) between streets 4 and $\mathrm{C}$. The markers $(\bullet)$ indicate the moment when the water depth reaches $99 \%$ of its ultimate value.

sufficiently gradual, i.e. that the characteristic timescales of the flood waves remain above $20-45 \mathrm{~min}$.

\section{Conclusion}

To investigate the flow characteristics in urbanized floodplains, here we considered the $5 \mathrm{~m} \times 5 \mathrm{~m}$ Icube Laboratory model of a typical European urban district. It involves 14 streets of different widths, in which the inflow discharges could be controlled individually. The outflow discharges were measured downstream of each street, as well as the water profiles in the streets. The experimental observations were compared with the results of an existing shallow-water model.
Two test series were considered. In the first one, $50 \%$ of the inflow discharge was injected through the west face of the model and $50 \%$ through the north face. The partition of the outflow discharge between the downstream faces (east and south) did not change by more than $2 \%$ as the total inflow was varied by 1 order of magnitude (between 10 and $100 \mathrm{~m}^{3} \mathrm{~h}^{-1}$ ). Similarly, the observed portion of outflow discharge in each street remained virtually independent of the total inflow. The numerical model succeeds in predicting the flow partition between the east and south faces accurately, whereas it overestimates the outflow through the widest streets (by 10 to $30 \%$ ) and underestimates the outflow in narrower streets.

Drops in the free surface profiles were observed downstream of each intersection. Between the intersections, the water depths remain fairly constant. In general, the computed water depths overestimate the experimental observations, by $1 \%$ (lowest total inflow) up to about $10 \%$ on average (highest total inflow). This overestimation of the overall flow resistance is consistent with the staircase representation of complex geometries when using a Cartesian grid.

The roughness parameter has very little influence on the computed results. Some features of the velocity field are predicted more realistically when a depth-averaged $k-\varepsilon$ turbulence model is used (e.g. shape and length of recirculation zones). The cell size was chosen to correspond to a grid refinement which may realistically be used in practice (about 5 to 12 cells over the width of the streets).

In a second series of tests, the partition of the inflow discharge between the west and north faces was varied systematically by steps of $10 \%$ between $\varphi_{\text {west }}=0 \%$ (inflow through the north face only) and $\varphi_{\text {west }}=100 \%$ (inflow through the west face only) for a constant total inflow. The relative influence of a change in $\varphi_{\text {west }}$ was fairly well reproduced by the numerical model, despite remaining overestimations of the outflow through the widest streets and viceversa for the narrower streets. 
The upscaling of the present findings to real-world applications was discussed. In particular, the influence of the roughness parameter is expected to become significantly stronger on the prototype scale due to the combined effect of a lower height-to-width ratio and a relatively higher roughness height characterizing real urban settings.

To overcome the influence of the Cartesian grid on the flow computations, a subgrid model based on porosity parameters was implemented. It leads to substantially better predictions of the outflow discharges at the street level.

In the future, velocity measurements and more detailed water level measurements will be performed in the near-field of the street intersections. The present research will also be extended to investigate the hydrodynamic characteristics of unsteady inundation flow in urbanized floodplains, as well as the influence of the bottom slope. Several other processes have not yet been considered and should be addressed in subsequent studies, such as flow within the buildings, morphodynamic changes and the transport of debris by the inundation flow.

\section{The Supplement related to this article is available online at doi:10.5194/nhess-16-1413-2016-supplement.}

Acknowledgements. The Icube Laboratory experimental model was funded by the Alsacian network of laboratories in Environmental Engineering and Sciences and the Fluid Mechanics research team of the Icube laboratory. The authors are grateful to the Icube Laboratory technicians (Martin Fisher, Johary Rasamimanana and Abdel Azizi) and the PhD students (Hakim Ben-Slimane, Vivien Schmitt, Noëlle Duclos, Alain Petit-Jean and Sandra Isel) for their priceless contribution to the building of the experimental set-up. Special thanks are also expressed to Quentin Araud who conducted most of the experiments.

Part of this research was funded through the ARC grant for Concerted Research Actions, financed by the Wallonia-Brussels Federation. The authors gratefully acknowledge Mathieu Debaucheron who contributed to some of the numerical computations.

Edited by: A. Günther

Reviewed by: two anonymous referees

\section{References}

An, H., Yu, S., Lee, G., and Kim, Y.: Analysis of an open source quadtree grid shallow water flow solver for flood simulation, Quatern. Int., 384, 118-128, 2015.

Araud, Q.: Simulation des écoulements en milieu urbain lors d'un événement pluvieux extrême, $\mathrm{PhD}$ thesis, Université de Strasbourg, Strasbourg, 2012.

Bates, P. D., Horritt, M. S., and Fewtrell, T. J.: A simple inertial formulation of the shallow water equations for efficient twodimensional flood inundation modelling, J. Hydrol., 387, 33-45, 2010.
Bazin, P. H.: Flows during floods in urban areas: influence of the detailed topography and the exchanges with the sewer system, $\mathrm{PhD}$ dissertation, Université Claude Bernard - Lyon I, Lyon, p. 293, 2013.

Bazin, P.-H., Nakagawa, H., Kawaike, K., Paquier, A., and Mignot, E.: Modeling flow exchanges between a street and an underground drainage pipe during urban floods, J. Hydraul. Eng., 140, 04014051, doi:10.1061/(ASCE)HY.1943-7900.0000917, 2014.

Beckers, A., Dewals, B., Erpicum, S., Dujardin, S., Detrembleur, S., Teller, J., Pirotton, M., and Archambeau, P.: Contribution of land use changes to future flood damage along the river Meuse in the Walloon region, Nat. Hazards Earth Syst. Sci., 13, 2301-2318, doi:10.5194/nhess-13-2301-2013, 2013.

Brazdova, M. and Riha, J.: A simple model for the estimation of the number of fatalities due to floods in central Europe, Nat. Hazards Earth Syst. Sci., 14, 1663-1676, doi:10.5194/nhess-141663-2014, 2014.

Bruwier, M., Erpicum, S., Pirotton, M., Archambeau, P., and Dewals, B. J.: Assessing the operation rules of a reservoir system based on a detailed modelling chain, Nat. Hazards Earth Syst. Sci., 15, 365-379, doi:10.5194/nhess-15-365-2015, 2015.

Camnasio, E., Erpicum, S., Archambeau, P., Pirotton, M., and Dewals, B.: Prediction of mean and turbulent kinetic energy in rectangular shallow reservoirs, Eng. Appl. Comput. Fluid Mech., 8, 586-597, 2014.

Causon, D., Ingram, D., Mingham, C., Yang, G., and Pearson, R.: Calculation of shallow water flows using a Cartesian cut cell approach, Adv. Water Resour., 23, 545-562, 2000.

Choi, S.-U. and Garcia, M. H.: $k-\hat{\mathrm{I}} \mu$ turbulence modeling of density currents developing two dimensionally on a slope, J. Hydraul. Eng., 128, 55-63, 2002.

Costabile, P. and Macchione, F.: Enhancing river model set-up for 2-D dynamic flood modelling, Environ. Model. Softw., 67, 89107, 2015.

de Moel, H., van Alphen, J., and Aerts, J. C. J. H.: Flood maps in Europe - methods, availability and use, Nat. Hazards Earth Syst. Sci., 9, 289-301, doi:10.5194/nhess-9-289-2009, 2009.

Detrembleur, S., Stilmant, F., Dewals, B., Erpicum, S., Archambeau, P., and Pirotton, M.: Impacts of climate change on future flood damage on the river Meuse, with a distributed uncertainty analysis, Nat. Hazards, 77, 1533-1549, 2015.

Dewals, B. J., Kantoush, S. A., Erpicum, S., Pirotton, M., and Schleiss, A. J.: Experimental and numerical analysis of flow instabilities in rectangular shallow basins, Environ. Fluid Mech., 8, 31-54, 2008.

Domeneghetti, A., Carisi, F., Castellarin, A., and Brath, A.: Evolution of flood risk over large areas: Quantitative assessment for the Po river, J. Hydrol., 527, 809-823, 2015.

Dottori, F., Di Baldassarre, G., and Todini, E.: Detailed data is welcome, but with a pinch of salt: Accuracy, precision, and uncertainty in flood inundation modeling, Water Resour. Res., 49, 6079-6085, 2013.

El Kadi Abderrezzak, K., Paquier, A., and Mignot, E.: Modelling flash flood propagation in urban areas using a two-dimensional numerical model, Nat. Hazards, 50, 433-460., 2009.

El Kadi Abderrezzak, K., Lewicki, L., Paquier, A., Riviere, N., and Travin, G.: Division of critical flow at three-branch open-channel intersection, J. Hydraul. Res., 49, 231-238, 2011. 
Ernst, J., Dewals, B. J., Detrembleur, S., Archambeau, P., Erpicum, S., and Pirotton, M.: Micro-scale flood risk analysis based on detailed 2D hydraulic modelling and high resolution geographic data, Nat. Hazards, 55, 181-209, 2010.

Erpicum, S., Meile, T., Dewals, B. J., Pirotton, M., and Schleiss, A. J.: 2D numerical flow modeling in a macro-rough channel, Int. J. Numer. Meth. Fluids, 61, 1227-1246, 2009.

Erpicum, S., Dewals, B., Archambeau, P., Detrembleur, S., and Pirotton, M.: Detailed inundation modelling using high resolution DEMs, Eng. Appl. Comput. Fluid Mech., 4, 196-208, 2010a.

Erpicum, S., Dewals, B., Archambeau, P., and Pirotton, M.: Dam break flow computation based on an efficient flux vector splitting, J. Comput. Appl. Math., 234, 2143-2151, 2010 b.

Ishigaki, T., Toda, K., and Inoue, K.: Hydraulic model tests of inundation in urban area with underground space, Theme B, Proc. of XXX IAHR Congress, August 2003, Greece, 487-493, 2003.

Kellermann, P., Schäbel, A., Kundela, G., and Thieken, A. H.: Estimating flood damage to railway infrastructure - The case study of the March River flood in 2006 at the Austrian Northern Railway, Nat. Hazards Earth Syst. Sci., 15, 2485-2496, doi:10.5194/nhess-15-2485-2015, 2015.

Kim, B., Sanders, B. F., Schubert, J. E., and Famiglietti, J. S.: Mesh type tradeoffs in 2D hydrodynamic modeling of flooding with a Godunov-based flow solver, Adv. Water Resour., 68, 42-61, 2014.

Kim, B., Sanders, B. F., Famiglietti, J. S., and Guinot, V.: Urban flood modeling with porous shallow-water equations: A case study of model errors in the presence of anisotropic porosity, J. Hydrol., 523, 680-692, 2015.

Kim, H.-J. and Cho, Y.-S.: Numerical model for flood routing with a Cartesian cut-cell domain, J. Hydraul. Res., 49, 205-212, 2011.

Kreibich, H., Van Den Bergh, J. C. J. M., Bouwer, L. M., Bubeck, P., Ciavola, P., Green, C., Hallegatte, S., Logar, I., Meyer, V., Schwarze, R., and Thieken, A. H.: Costing natural hazards, Nat. Clim. Change, 4, 303-306, 2014.

Li, C. W. and Zeng, C.: Flow division at a channel crossing with subcritical or supercritical flow, Int. J. Numer. Meth. Fluids, 62, 56-73, 2010.

Lipeme Kouyi, G., Rivière, N., Vidalat, V., Becquet, A., Chocat, B., Guinot, V.: Urban flooding: One-dimensional modelling of the distribution of the discharges through cross-road intersections accounting for energy losses, Water Sci. Technol., 61, 2021-2026, 2010.

Merz, B., Vorogushyn, S., Uhlemann, S., Delgado, J., and Hundecha, Y.: HESS Opinions "More efforts and scientific rigour are needed to attribute trends in flood time series", Hydrol. Earth Syst. Sci., 16, 1379-1387, doi:10.5194/hess-16-13792012, 2012.

Mignot, E., Paquier, A., and Haider, S.: Modeling floods in a dense urban area using 2D shallow water equations, J. Hydrol., 327, 186-199, 2006.
Mignot, E., Paquier, A., and Rivièe, N.: Experimental and numerical modeling of symmetrical four-branch supercritical cross junction flow, J. Hydraul. Res., 46, 723-738, 2008.

Mignot, E., Zeng, C., Dominguez, G., Li, C.-W., Rivière, N., and Bazin, P.-H.: Impact of topographic obstacles on the discharge distribution in open-channel bifurcations, J. Hydrol., 494, 10-19, 2013.

Neal, J. C., Bates, P. D., Fewtrell, T. J., Hunter, N. M., Wilson, M. D., and Horritt, M. S.: Distributed whole city water level measurements from the Carlisle 2005 urban flood event and comparison with hydraulic model simulations, J. Hydrol., 368, 42-55, 2009.

Neary, V., Sotiropoulos, F., and Odgaard, A.: Three-Dimensional Numerical Model of Lateral-Intake Inflows, J. Hydraul. Eng., 125, 126-140, 1999.

Paquier, A., Tachrift, H., Riviere, N., and El kadi Abderrezzak, K.: Assessing the effects of two non-structural flood mitigation measures using laboratory and real cases, Road map towards a flood resilient urban environment, Proceedings Final conference of the COST action C22, 26-27 November 2009, Paris, France, p. 8, 2009.

Rivière, N., Travin, G., and Perkins, R. J.: Subcritical open channel flows in four branch intersections, Water Resour. Res., 47, W10517, doi:10.1029/2011WR010504, 2010.

Rivière, N., Travin, G., and Perkins, R. J.: Transcritical flows in three and four branch open-channel intersections, J. Hydraul. Eng., 140, 04014003, doi:10.1061/(ASCE)HY.19437900.0000835, 2014.

Roache, P. J.: Perspective: a method for uniform reporting of grid refinement studies, J. Fluids Eng., 116, 405-413, 1994.

Sanders, B. F., Schubert, J. E., and Gallegos, H. A.: Integral formulation of shallow-water equations with anisotropic porosity for urban flood modeling, J. Hydrol., 362, 19-38, 2008.

Sattar, A. M. A., Kassem, A. A., and Chaudhry, M. H.: Case study: 17th street canal breach closure procedures, J. Hydraul. Eng., 134, 1547-1558, 2008.

Schubert, J. E. and Sanders, B. F.: Building treatments for urban flood inundation models and implications for predictive skill and modeling efficiency, Adv. Water Resour., 41, 49-64, 2012.

Soares-Frazão, S. and Zech, Y.: Dam-break flow through an idealised city, J. Hydraul. Res., 46, 648-658, 2008.

Vorogushyn, S. and Merz, B.: Flood trends along the Rhine: the role of river training, Hydrol. Earth Syst. Sci., 17, 3871-3884, doi:10.5194/hess-17-3871-2013, 2013.

Weber, L. J., Schumate, E. D., and Mawer, N.: Experiments on flow at a $90^{\circ}$ open-channel junction, J. Hydraul. Eng., 127, 340-350, 2001.

Zech, Y. and Soares-Frazão, S.: Dam-break flow experiments and real-case data. A database from the European IMPACT research, J. Hydraul. Res., 45, 5-7, 2007. 